African Journal of Biomedical Research, Vol. 7 (2004); 51 - 57

ISSN 1119 - 5096 @ Ibadan Biomedical Communications Group

Full Length Research Article

\title{
ORAL TEMPERATURE AND CARDIOVASCULAR RESPONSES OF APPARENTLY HEALTHY SUBJECTS TO PASSIVE AND ACTIVE WARM-UP.
}

\author{
*ADEGOKE, B.O.A., **OGWUMIKE, O.O., *MARUF, F.A. \\ *Department Of Physiotherapy, College of Medicine, University College Hospital, Ibadan. \\ ${ }^{*}$ Department of Physiology, Obafemi Awolowo College Of Health Sciences, Olabisi Onabanjo \\ University, Ago-Iwoye.
}

This study investigated and compared the effects of active and passive warm-up on oral temperature and cardiovascular parameters of forty (20 males and 20 females) apparently

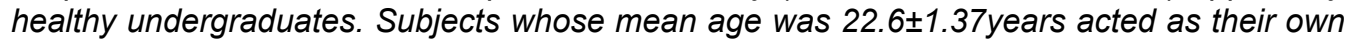
controls. During active warm-up (AWU) subjects rode on an unloaded bicycle ergometer for 15 minutes while they received infra-red radiation to the lower extremities for 15 minutes during passive warm-up (PWU). Oral temperature (OT) and cardiovascular parameters of systolic blood pressure (SBP), diastolic blood pressure (DBP), heart rate (HR) and ratepressure product (RPP) were measured before and after each type of warm-up. The data were summarized using mean and standard deviation and further analyzed using independent (unpaired) t-test with $\alpha$ set at 0.05.Results showed that there were no significant differences between pre- and post PWU cardiovascular parameters of the subjects. In contrast, significant differences were observed between the pre- and post- AWU cardiovascular parameters of the subjects. However, oral temperature responses to both $A W U$ and PWU were statistically significant. Further, the responses (mean changes) of HR, $S B P$ and RPP to AWU were significantly different. There were also no significant differences between the responses of male and female subjects to either AWU or PWU. Due to the significant increases in HR, SPB and RPP following AWU it was suggested that care should be taken when including AWU in treatment programmes of patients with or suspected of having cardiovascular problems.

Key Words: Cardiovascular responses, oral temperature, warm-up, passive, active, bicycle ergometry.

*Author for Correspondence [(E-mail: badegoke@comui.edu.ng Tel. (234-2-2410088; 234-804-210-8765).

\section{INTRODUCTION}

Metabolic processes in the cell are temperature-regulated and there is a 13 percent increase in the metabolic rate for each degree of temperature increase (Astrand and Rodahl, 1977). Warm-up is therefore usually an integral part of an athletic event as it helps prepare the athlete's body and mind for the workout or competition (Roy and Richard, 1983). Two basic types of warm-up are recognized active and passive warm-up. Active warm-up (AWU) raises the temperature through the movement of the various muscle groups. It is further sub-divided into general (non- specific) and specific warm-up. General warm-up consists of exercises like calisthenics, stretching and general body movements which are unrelated to the specific neuromuscular actions of the anticipated performance (McArdle et al, 1996). On the other hand, specific warm-up provides a skill rehearsal for the actual activity for which the athlete is preparing. During passive warm-up (PWU) the body temperature is raised by some external agents such as heat application, massage, diathermy etc. (Wilmore, 1982).

All types of warm-up are believed to be effective provided there is $1^{\circ} \mathrm{C}-2^{\circ} \mathrm{C}$ 
increase in the rectal temperature (DeVries, 1980; Roy and Richard, 1983). This usually coincides with the onset of sweating in normal environmental condition hence onset of sweating could be a good indicator of adequate warm-up (Roy and Richard, 1983; Shellock, 1983). The oral temperature is usually about $0.5{ }^{\circ} \mathrm{C}$ lower than the rectal temperature (Ganong, 2001) but not significantly different from it (Osinusi and Njinyam, 1977). The oral temperature is hence a good predictor of the core temperature and could hence be used to assess the effectiveness of a warm-up.

Provided the body temperature is sufficiently elevated, warm-up improves performance by facilitating accuracy, movement time, range of motion and strength in movements of selected body parts (Franks, 1972). Animal studies have further indicated that greater forces and increases in muscle length are required to injure a warmed than a cold muscle (McArdle et al, 1996). The study by Pope et al, (2000) reported similar rates of injuries in subjects involved in a 12- week programme of warm-up exercises with and without stretching- a usual component of active warm-up. However, since the study did not include a control group, conclusions on the effect of warm-up on injuries could hence not be drawn.

Active warm up is routine in athletics while PWU, which is not practical for athletics, is routinely used in physiotherapy practice for relieving pain and preparing the body for therapeutic exercises. In view of the hypothesis that an effective warm-up must raise the rectal temperature by $1^{\circ} \mathrm{C}-2^{\circ} \mathrm{C}$, this study was designed primarily to evaluate and compare the oral temperature responses of apparently healthy college-age students to AWU and PWU. It also compared the cardiovascular responses of the subjects to the two types of warm-up.

\section{MATERIALS AND METHODS Materials}

Subjects: Forty $(20$ males and 20 females) apparently healthy undergraduate clinical students of the University of Ibadan aged 20-30 years participated in this study.
Subjects were volunteers who had no contraindication to infrared radiation and no dysfunction that might preclude their riding on a bicycle ergometer. All subjects also agreed to avoid activities such as ingestion of cold or hot fluid, gum-chewing, smoking and mouth breathing that may affect their oral temperature (Ganong, 2001) before coming for the tests.

Equipment: The following equipment were used for data collection

1. Bicycle ergometer - A lower extremity bicycle ergometer (Tunturi) was used for active warm-up.

2. Tunnel bath - A tunnel bath with six 40Watts electric bulbs was used to supply the infrared for passive warm-up.

3. A clinical thermometer (Oralprismatic C scale) - was used to measure subjects' oral temperature

4. Sphygmomanometer and stethoscope - A mercury-in-glass sphygmomanometer and a Lithman's stethoscope (USA) were used to measure subjects' cardiovascular parameters.

\section{Methods}

The rationale behind and procedure for the study were explained to the subjects and their written consent to participate was sought and obtained. The approval of the joint U.I/U.C.H ethical committee was also sought and obtained. On arrival at the venue of the study, subjects rested for five minutes before basal values of heart rate (HR), systolic blood pressure (SBP), diastolic blood pressure (DBP) and oral temperature (OT) were taken while the rate-pressure product (RPP) was calculated using the standard formula of : RPP $=\mathrm{HR} \times \mathrm{SBP}$ (McArdle et al, 1996)

The cardiovascular parameters were taken using the methods described by Kispert (1988) while oral temperature measurement followed the format of Osinusi and Njinyam (1997). Active warm up was achieved by asking the subject to ride on an unloaded lower extremity bicycle ergometer set at a speed of 60 metres per second for 15 minutes. During PWU, the subject was in a long- sitting on a plinth with a backrest and 
his lower limbs from the proximal aspect of the thighs to the feet were irradiated with infrared from a tunnel bath for 15 minutes.

Post warm-up, oral temperature and cardiovascular parameters of the subjects were re-taken. Each subject acted as his own control but the order of warm up was determined by the availability of the equipment since there was one item each of the tunnel bath and bicycle ergometer. The interval between the two types of warm-up was however kept at one week while all tests were carried out between 12.00 noon and $3.00 \mathrm{pm}$ to ensure that all subjects were exposed to similar room temperature and test condition.

\section{Data Analysis}

Descriptive statistics of mean and standard deviation were used to summarize the characteristic of the subjects and to describe their performances on AWU and PWU variables. Independent t-test was used to compare the subjects' oral temperature and cardiovascular responses to AWU and PWU. Independent t-test was also used to compare the oral temperature and cardiovascular responses of male and female subjects to AWU and PWU. Significant level $(\alpha)$ was set at 0.05 .

Table 2:

Pre - and Post-Warm up Cardiovascular Parameters And Oral Temperature Of Subjects

\begin{tabular}{|c|c|c|c|c|c|c|c|c|}
\hline \multirow{3}{*}{ PARAMETERS } & & & & & \multicolumn{4}{|c|}{ WARM UP TYPES } \\
\hline & \multicolumn{4}{|c|}{ ACTIVE WARM UP } & \multicolumn{4}{|c|}{ PASSIVE WARM UP } \\
\hline & $\begin{array}{l}\text { Pre- } \\
\text { warm up } \\
\text { X } \pm \text { S.D }\end{array}$ & $\begin{array}{l}\text { Post- } \\
\text { warm up } \\
\text { X } \pm \text { S.D }\end{array}$ & t-value & $p$ & $\begin{array}{l}\text { Pre- warm up } \\
X \pm \text { S.D }\end{array}$ & $\begin{array}{l}\text { Post-warm up } \\
\mathrm{X} \pm \text { S.D }\end{array}$ & $\begin{array}{l}\mathrm{t}- \\
\text { value }\end{array}$ & $\mathrm{P}$ \\
\hline HR (beats/min) & $\begin{array}{l}78.25 \\
+10.19\end{array}$ & $\begin{array}{l}94.45 \\
+15.10\end{array}$ & $9.76^{*}$ & 0.00 & $\begin{array}{l}77.35 \\
+10.85\end{array}$ & $\begin{array}{l}76.60 \\
+10.24\end{array}$ & 0.88 & 0.37 \\
\hline $\mathrm{SBP}(\mathrm{mmHg})$ & $\begin{array}{l}107.23 \\
+9.79\end{array}$ & $\begin{array}{r}116.30 \\
+13.98 \\
\end{array}$ & $4.12^{*}$ & 0.00 & $\begin{array}{r}103.65 \\
+12.17 \\
\end{array}$ & $\begin{array}{r}103.58 \\
+11.01 \\
\end{array}$ & 0.09 & .95 \\
\hline $\mathrm{DBP}(\mathrm{mmHg})$ & $\begin{array}{l}70.95 \\
+8.42 \\
\end{array}$ & $\begin{array}{l}67.50 \\
+9.67 \\
\end{array}$ & $3.00^{*}$ & 0.01 & $\begin{array}{l}65.08 \\
+10.57\end{array}$ & $\begin{array}{l}65.13 \\
+10.46 \\
\end{array}$ & 0.03 & 0.18 \\
\hline $\mathrm{RPP}(\mathrm{mmHg} / \mathrm{min})$ & $\begin{array}{l}8539.25 \\
+1807.60 \\
\end{array}$ & $\begin{array}{l}11054.00 \\
+2772.9 \\
\end{array}$ & $10.05^{*}$ & 0.00 & $\begin{array}{l}8028.20 \\
+1607.88 \\
\end{array}$ & $\begin{array}{l}7068.7 \\
+1633.10 \\
\end{array}$ & 0.06 & 0.61 \\
\hline $\mathrm{OT}\left({ }^{0} \mathrm{C}\right)$ & $\begin{array}{l}36.97 \\
+0.19 \\
\end{array}$ & $\begin{array}{l}37.13 \\
+0.23 \\
\end{array}$ & $5.07^{*}$ & 0.00 & $\begin{array}{l}36.93 \\
+0.22 \\
\end{array}$ & $\begin{array}{l}37.16 \\
+0.19 \\
\end{array}$ & 6.90 & .00 \\
\hline
\end{tabular}

*Indicates significant difference

$H R=$ Heart rate; $S B P=$ Systolic blood pressure; $D B P=$ Diastolic blood pressure; $R P P=$ Rate-pressure product; $\mathrm{OT}=$ Oral temperature

\section{RESULTS}

\section{Characteristics of Subjects}

Subjects were aged 20-27years with the males aged $23.60 \pm 1.34$ years and the females aged 21.95 \pm 1.05 years (Table 1). The males were significantly older $(P=0.001)$ than the females

Table 1: Comparison of Age of Subjects

\begin{tabular}{|c|c|c|c|c|c|}
\hline \multirow[t]{2}{*}{ SEX } & \multicolumn{5}{|c|}{ AGE (YEARS) } \\
\hline & Minimum & Maximum & $\overline{X+S . D}$ & $\mathrm{t}$ & $P$ \\
\hline $\bar{M}$ & 22.0 & 27.0 & $\begin{array}{r}23.60 \\
\pm 1.34\end{array}$ & & \\
\hline $\mathrm{F}$ & 20.0 & 24.0 & $\begin{array}{r}21.95 \\
\pm 1.05 \\
\end{array}$ & $3.54^{*}$ & 0.000 \\
\hline All & 20.0 & 27.0 & $\begin{array}{l}22.63 \\
\pm 1.37\end{array}$ & & \\
\hline
\end{tabular}

\section{Oral Temperature (OT) Response}

There was significant difference $(p=0.000)$ between the mean pre-AWU oral temperature $\left(36.97 \pm 0.19^{\circ} \mathrm{C}\right)$ and the mean post-AWU oral temperature $\left(37.13 \pm 0.23^{\circ} \mathrm{C}\right)$. Also there was significant difference $(p=0.000)$ between the mean pre-PWU oral temperature $\left(36.98 \pm 0.22^{\circ} \mathrm{C}\right)$ and the mean post-AWU oral temperature $\left(37.16 \pm 0.19^{\circ} \mathrm{C}\right)$ (Table 2). 
Table 3:

Comparison of Cardiovascular and Oral Temperature Responses of Subjects to Passive and Active Warm Ups.

\begin{tabular}{|c|c|c|c|c|c|}
\hline \multirow{2}{*}{$\begin{array}{ll}\text { Warm } & \text { Up } \\
\text { Types } & \end{array}$} & \multicolumn{5}{|c|}{ PARAMETERS } \\
\hline & $\begin{array}{l}\text { Heart rate } \\
\text { (beats } / \mathrm{min} \text { ) }\end{array}$ & $\begin{array}{l}\text { Systolic blood } \\
\text { pressure }(\mathrm{mmHg})\end{array}$ & $\begin{array}{l}\text { Diastolic blood } \\
\text { pressure }(\mathrm{mmHg})\end{array}$ & $\begin{array}{l}\text { Rate-pressure } \\
\text { product }\end{array}$ & $\begin{array}{l}\text { Oral temperature } \\
{ }^{0} \mathrm{C}\end{array}$ \\
\hline $\begin{array}{l}\text { AWU } \\
(n=40)\end{array}$ & $16.35 \pm 10.34$ & $7.38 \pm 9.02$ & $-3.45 \pm 7.29$ & $2467.75 \pm 1577.57$ & $0.16 \pm 0.19$ \\
\hline $\begin{array}{l}\text { PWU } \\
(n=40)\end{array}$ & $-0.75 \pm+5.41$ & $-0.08 \pm 7.20$ & $-2.08 \pm 8.20$ & $-61.00 \pm 741.28$ & $0.18 \pm 0.16$ \\
\hline t-value & 9.27 & 4.19 & 0.79 & 9.18 & 0.382 \\
\hline$p$-value & $0.000^{*}$ & $0.000^{*}$ & 0.43 & $0.000^{*}$ & 0.704 \\
\hline
\end{tabular}

* Indicates significant difference; $A W U$ = Active warm up; $P W U$ = Passive warm up

Table 4:

Comparison Of Cardiovascular And Oral Temperature Responses Of Male and Female Subjects To Active And Passive Warm Ups.

\begin{tabular}{|c|c|c|c|c|c|c|c|c|c|c|}
\hline & \multicolumn{5}{|c|}{ ACTIVE WARM -UP } & \multicolumn{3}{|c|}{ PASSIVE } & \multicolumn{2}{|l|}{ WARM UP } \\
\hline & HR & SBP & DBP & RPP & OT & HR & SBP & DBP & RPP & OT \\
\hline MALE & 15.40 & 5.35 & 2.55 & 2186.30 & 0.18 & 0.50 & -1.80 & -1.65 & -164.00 & 0.19 \\
\hline$(n=20)$ & \pm 9.85 & \pm 10.23 & \pm 7.56 & \pm 1645.80 & \pm 0.22 & \pm 5.39 & \pm 8.70 & \pm 8.70 & \pm 889.50 & \pm 0.16 \\
\hline FEMALE & 17.30 & 9.80 & 4.35 & 2748.70 & 0.15 & -1.00 & 1.65 & -2.50 & 42.00 & 0.17 \\
\hline$(n=20)$ & \pm 11.2 & \pm 7.22 & \pm 7.07 & \pm 1495.52 & \pm 0.15 & \pm 5.56 & \pm 4.91 & \pm 7.86 & \pm 660.69 & \pm 0.60 \\
\hline t-value & 0.58 & 1.59 & 0.78 & 1.13 & 0.50 & 0.30 & 1.54 & 0.32 & 0.88 & 0.39 \\
\hline p-value & $0.57^{+}$ & $0.12^{+}$ & $0.44^{+}$ & $0.27^{+}$ & $0.62^{+}$ & $0.77^{+}$ & $0.13^{+}$ & $0.75^{+}$ & $0.39^{+}$ & $0.70^{+}$ \\
\hline
\end{tabular}

${ }^{+}$Indicates no significant difference; HR = Heart rate (beats/min); SBP = Systolic blood pressure $(\mathrm{mmHg}) ; D B P=$ Diastolic blood pressure $(\mathrm{mmHg}) ; R P P=$ Rate - Pressure product $(\mathrm{mmHg} / \mathrm{min}) ; \mathrm{OT}=$ Oral temperature $\left({ }^{\circ} \mathrm{C}\right)$

Table 3 shows that there was no significant difference in the OT response to AWU and PWU $(p=0.59)$. Also, male and female subjects did not differ significantly $(p=0.75)$ in their OT responses to either AWU or PWU (Table 4).

\section{Cardiovascular parameters}

The pre and post-warm up cardiovascular parameters of subjects are presented in Table 2. Independent t-test showed statistically significant differences between the pre- and post- AWU values of HR $\quad(p=0.000)$, SBP $\quad(p=0.000)$, DBP $(p=0.010)$ and RPP $(p=0.000)$. There were however no significant differences between the pre and post $P W U$ values of $H R$ $(p=0.37)$, SBP $(p=0.95)$, DBP $(p=0.18)$ and $\operatorname{RRP}(p=0.61)$. Indeed, the post-AWU values of HR, SBP, and RPP were significantly higher than the pre-AWU values while the
post-AWU diastolic blood pressure was significantly lower.

The cardiovascular responses of the subjects to AWU and PWU are compared in Table 3. The HR, SBP and RPP responses of the subjects to AWU were significantly greater $(p=0.00)$ than their responses to PWU. The mean response of $3.45 \pm 7.29 \mathrm{mmHg}$ of DBP to AWU was also higher but not significantly different $(p=0.38)$ from the response of $-2.08 \pm 8.20 \mathrm{mmHg}$ to PWU.

The cardiovascular responses of male and female subjects to either AWU or PWU are compared in Table 4. There were no significant differences $(P>0.12)$ in the responses of male and female subjects to either AWU or PWU. However, in absolute terms, the responses of females to AWU were greater than those of males. 


\section{DISCUSSION}

The primary objective of this work was to evaluate and compare the oral temperature responses of apparently healthy, undergraduate students to active and passive warm up and hence evaluate the effectiveness of fifteen minutes of both warm up techniques. The outcome of the study has shown that both AWU and PWU resulted in statistically significant increases in oral temperature of the subjects. This finding is in conformity with the observations of Wessman and Kottke (1967) and O'Brien et al (1997). Wessman and Kottke (1967) reported a significant increase in oral temperature following the application of short wave diathermy (a source of deep heat and hence passive warm up) to the abdomen. O'Brien et al (1997) also reported increases in the rectal temperature of their subjects after both passive and active warm ups. However, our study did not show any significant difference between the oral temperature responses of subjects to PWU and PWU. This is contrary to the observation of O'Brien et al, (1997) that the rectal temperature was increased more by AWU than PWU. It is noteworthy that in our study, both lower limbs had active and passive warm ups while only the quadriceps had AWU in the study by O'Brien et al (1967). It is hence plausible that the larger and more proportional body surface exposed to PWU in our study explains why the oral temperature responses to AWU and PWU were not significantly different. Although the rectal temperature monitored by O'Brien et al (1997) is an accurate and reliable indicator of the core temperature, the oral temperature monitored in our study has been found not to be significantly different from the rectal temperature (Osinusi and Njiyam, 1997, Lodha et al, 2000). We could not use rectal temperature in this study because our subjects found the method inconvenient and objectionable. Akinbami and Sowumi (1991) have similarly described the rectal method of temperature measurement as unhygienic, distressing and embarrassing to adults and capable of spreading infection.
In view of the submission by Devries (1980) that a sufficient warm up should be able to raise the rectal temperature by $1^{\circ} \mathrm{C}$ $2^{0} \mathrm{C}$, this study also aimed at assessing the effectiveness of the warm up techniques used in our study. The miserably low magnitudes of oral temperature responses achieved by the two warm up techniques suggest that the warm up used in our study might not have been adequate. Although the oral temperature is usually $0.5^{\circ} \mathrm{C}$ lower than the rectal temperature, (Ganong, 1995), the low oral temperature responses may indeed indicate that the duration and/or intensity of the warm ups were inadequate.

The HR, SBP, and RPP responses of subjects in this study to AWU were in line with the known responses of subjects to sub- maximal active exercises - increases in $H R$, SBP and RPP in proportion to the demands of the exercise (Suzuki, 1980; Negus et al, 1987). The HR response of subjects to AWU in this study agreed with the observation of Peel and Alland (1990) that active exercises resulted in significant increases in heart rate. Our finding of significant increase in SBP following AWU however contradicted the observation of Peel and Alland (1990) that SBP did not change significantly after isokinetic trunk exercise. Dynamic leg exercises like cycling are known to be associated with a number of complex haemodynamic changes in normal subjects with concomitant increases in both HR and blood pressure (Shepherd, 1978) as observed in our study. The significant decrease in DBP following AWU was however inconsistent with literature as an acute bout of exercise is known to cause little or no change in DBP; an increase in DBP being considered as abnormal (Wilmore, 1982). Peel and Alland (1990) have however similarly reported significant decrease in DBP after an isokinetic trunk exercise by their subjects. The heart rate and blood pressure responses during exercises are measures of the stress on the cardiovascular system (Peel and Alland, 1990) while the rate - pressure product (RPP) is an index of relative cardiac work and highly related to directly measured myocardial oxygen up-take and coronary blood flow in healthy subjects (McArdle et al, 
1996). The significant increase in the RPP following AWU was therefore expected, as there were corresponding increases in $\mathrm{HR}$ and SBP.

Contrary to the finding of Wessman and Kottke (1967), we did not observe significant increase in HR following PWU. We however want to believe that the disparity in the findings of the two studies might have been due to the fact that larger body surface was warmed in our study with concomitant more extensive vasodilatation and lower increase in HR than in the study by Wessman and Kottke (1967). The SBP and DBP responses of our subjects to PWU were however similar to the findings of Wessman and Kottke (1967) that both SBP and DBP did change significantly after the application of short-wave diathermy to the abdomen. Furthermore, as the subjects were in a somewhat state of rest during PWU, it was not unexpected that there was no significant difference between the pre- and post-PWU mean RPP of our subjects.

\section{Clinical Implication}

This study did not reveal any significant difference between the oral temperature responses of apparently healthy undergraduates to active and passive warmup thereby suggesting that both types of warm-up were equally effective. However, the finding that active warm-up resulted in significant increases in cardiovascular parameters while passive warm-up did not, suggested the need for caution when active warm-up as simple as stationary bicycle riding is included in the treatment programmes of patients with cardiovascular problems (hypertension and coronary heart disease). In such patients, passive warm up that has little or no effect on the cardiovascular parameters may be safer and readily substituted. Also, our finding may further highlight the need for individuals to have their blood pressure checked before increasing their physical activity level. In healthy athletes however, we support the continued use of specific warm-up as this better prepares the athlete for the event besides raising the body temperature.

\section{RECOMMENDATION}

Future studies could compare the effects of different duration of warm ups on axillary, oral and rectal temperature.

\section{REFERENCES}

Akinbami, F.O; Sowumi, O (1991): Body temperature in the Nigerian neonate comparison of axillary and rectal temperature. Afr. J. Med. Sci. 20, 49-51.

Astrand, P; Rodahl, K (1977): Textbook of Work Physiology - Physiological Basis of Exercises. New York, McGraw - Hill Book Company, 562-563.

DeVries, H.A. (1980): Physiology of Exercise for Physical Education and Athletics, $3^{\text {rd }} \mathrm{Ed}$, Dubuque, William C.Brown Co. Publishers.

Franks, B.D. (1972): Physical warm-up In: Ergogenic aids and muscular performance, Morgan W.P, (Ed), New York, Academic Press.

Ganong, W.F. (1995): Review of Medical Physiology. $17^{\text {th }}$ Ed, USA, Appleton and Lange, 195.

Kispert, C.P. (1988): Clinical measurements to assess cardiopulmonary functions. Phys. Ther. 67, 1886-1890.

Lodha, R; Mukerji, N; Sinha, N; Pandah, R.M.; Javies, Y. (2000): Is axillary temperature an appropriate surrogate for core temperature? Indian J. Pediatrics 67, 571-574.

McArdle, W.D; Katch, F.I; Katch, V.I. (1996): Exercise physiology: Energy, Nutrition and Human performance, $4^{\text {th }} \mathrm{Ed}$, Philadelphia, Lippincott Williams and Wilkins, 467-469.

Negus, R.A; Rippe, J.M.; Freedson, P; Michaels, J. (1987); Heart rate, blood pressure and oxygen consumption during orthopaedic rehabilitation exercise. J. Ortho. Sports. Phys. Ther. 28, 346-350.

O' Brien, B; Payne, W. (1977); A comparison of active and passive warm-up on energy system contribution and performance in moderate heat. Australian J. Sci Med. Sport. 29, 106-107.

Sinusi, K; Njinyam, M.N; (1997): Comparison of body temperatures taken at different sites and the reliability of axillary 
temperature in screening for fever. Afr. J. Med. Sci. 26, 163-166.

Peel, C; Alland, M.J. (1990): Cardiovascular responses to isokinetic exercise. Phys. Ther. 70, 503-510.

Pope, R.P; Herbert, R.D; Kirwan, J.D.: Graham, B.J. (2000): A randomized trial of pre-exercise stretching for prevention of lower limb injury, Med. Sci,. Sports and Exer. 32, 271-277.

Roy, S.; Richard, I. (1983): Sports Medicine: Prevention, Evaluation, Management and Rehabilitation. New Jersey, Prentice Hall Inc., 39-44

Shellock, F. G. (1983): Physiological benefits of warm-up. Phys. Sports. Med. 11, 134-138
Shepherd, J.T. (1987): Circulatory response to exercise in health. Circulation 76, V16V110.

Suzuki, Y. (1980): Mean arterial pressure, O2-uptake and muscle force time during dynamic and rhythmic static exercise in man with high percentage of fast and slow-twitch fibers. Eur. J. Appl. Physiol. 43, 844-852.

Wessman H.C; Kotte, F.J (1967): The effect of indirect heating on peripheral blood flow, pulse rate, blood pressure and temperature. Arch. Phys. Med. Rehab. 48, 567-578.

Wilmore, J. H. (1982): Ergonomic aids In Training for sports activity: The Physiological basis of the conditioning process. $2^{\text {nd }} \mathrm{Ed}$. London, Abbyn and Bacon, 199 - 208

Received: February 2003

Accepted in final form: May 2004 
